\section{OPEN ACCESS}

Edited by:

Oswaldo Valdes-Lopez, National Autonomous University of Mexico, Mexico

Reviewed by:

Rupesh Kailasrao Deshmukh, Laval University, Canada

Matthew Nicholas Nelson,

Royal Botanic Gardens, Kew, United Kingdom

*Correspondence: Swarup K. Parida swarup@nipgr.ac.in; swarupdbt@gmail.com

${ }^{\dagger}$ Present address: Akhilesh K. Tyagi,

Department of Plant Molecular Biology, University of Delhi South

Campus, New Delhi, India

FThese authors have contributed equally to this work.

Specialty section: This article was submitted to Crop Science and Horticulture, a section of the journal

Frontiers in Plant Science

Received: 19 December 2016 Accepted: 07 June 2017

Published: 11 July 2017

Citation:

Srivastava R, Upadhyaya HD, Kumar R, Daware A, Basu U,

Shimray PW, Tripathi S,

Bharadwaj C, Tyagi AK and Parida SK (2017) A Multiple QTL-Seq

Strategy Delineates Potential Genomic Loci Governing Flowering Time in Chickpea.

Front. Plant Sci. 8:1105. doi: 10.3389/fpls.2017.01105

\title{
A Multiple QTL-Seq Strategy Delineates Potential Genomic Loci Governing Flowering Time in Chickpea
}

\begin{abstract}
Rishi Srivastava ${ }^{1 \neq}$, Hari D. Upadhyaya² , Rajendra Kumar³, Anurag Daware1, Udita Basu', Philanim W. Shimray ${ }^{4}$, Shailesh Tripathi ${ }^{4}$, Chellapilla Bharadwaj4, Akhilesh K. Tyagi ${ }^{1 \dagger}$ and Swarup K. Parida ${ }^{1 *}$
\end{abstract}

\footnotetext{
${ }^{1}$ National Institute of Plant Genome Research, New Delhi, India, ${ }^{2}$ International Crops Research Institute for the Semi-Arid Tropics, Patancheru, India, ${ }^{3}$ U.P. Council of Agricultural Research, Lucknow, India, ${ }^{4}$ Division of Genetics, Indian Agricultural Research Institute, New Delhi, India
}

Identification of functionally relevant potential genomic loci using an economical, simpler and user-friendly genomics-assisted breeding strategy is vital for rapid genetic dissection of complex flowering time quantitative trait in chickpea. A highthroughput multiple QTL-seq strategy was employed in two inter (Cicer arietinum desi accession ICC $4958 \times$ C reticulatum wild accession ICC 17160)- and intra (ICC $4958 \times$ C. arietinum kabuli accession ICC 8261)-specific RIL mapping populations to identify the major QTL genomic regions governing flowering time in chickpea. The whole genome resequencing discovered 1635117 and 592486 SNPs exhibiting differentiation between early- and late-flowering mapping parents and bulks, constituted by pooling the homozygous individuals of extreme flowering time phenotypic trait from each of two aforesaid RIL populations. The multiple QTL-seq analysis using these mined SNPs in two RIL mapping populations narrowed-down two longer (907.1 kb and $1.99 \mathrm{Mb}$ ) major flowering time QTL genomic regions into the high-resolution shorter (757.7 kb and 1.39 Mb) QTL intervals on chickpea chromosome 4. This essentially identified regulatory as well as coding (non-synonymous/synonymous) novel SNP allelic variants from two efl1 (early flowering 1) and GI (GIGANTEA) genes regulating flowering time in chickpea. Interestingly, strong natural allelic diversity reduction (88-91\%) of two known flowering genes especially mapped at major QTL intervals as compared to that of background genomic regions (where no flowering time QTLs were mapped; 61.8\%) in cultivated vis-à-vis wild Cicer gene pools was evident inferring the significant impact of evolutionary bottlenecks on these loci during chickpea domestication. Higher association potential of coding non-synonymous and regulatory SNP alleles mined from efl1 (36-49\%) and Gl (33-42\%) flowering genes for early and late flowering time differentiation among chickpea accessions was evident. The robustness and validity of two functional allelic variants-containing genes localized at major flowering time QTLs was apparent by their identification from multiple intra-/inter-specific mapping populations of chickpea. The functionally relevant molecular tags delineated can be of immense use for deciphering the natural allelic diversity-based domestication pattern of flowering time and expediting genomics-aided crop improvement to develop early flowering cultivars of chickpea.

Keywords: chickpea, flowering time, multiple QTL-seq, QTL, SNP 


\section{INTRODUCTION}

Chickpea (Cicer arietinum L.) is one of the vital food legume crops represented by two of its major cultivar types- desi and kabuli (Kumar et al., 2011) which are thought to be domesticated along with the wild ancestor C. reticulatum at Fertile Crescent around 10000 years ago (Burger et al., 2008; Toker, 2009). Development of early-flowering/maturing stress tolerant cultivars with high seed and pod yield is the prime objective of the present genomics-assisted breeding research in chickpea (Hegde, 2010; Zaman-Allah et al., 2011). The number of days to flowering is a major seed and pod-yield component trait that highly acclimatizes with climate change, diverse environmental and a/biotic stress factors and photoperiod response along with various other growth/developmental-related traits (Aryamanesh et al., 2010; Kashiwagi et al., 2013; Daba et al., 2016). Therefore, implication of flowering time in defining productivity as well as developing stress tolerant cultivars is welldocumented in chickpea. Collectively, this infers that flowering time is a complex quantitative trait and it is governed by multiple major as well as minor genes/QTLs (quantitative trait loci). A strong impact of a known major evolutionary bottleneck- vernalization- on flowering time response during chickpea domestication infers that the flowering time is a most important domestication trait selected during breeding of presently cultivated desi and kabuli accessions (Abbo et al., 2014). The genetic dissection of complex flowering time quantitative trait by identifying the functionally relevant potential genes/alleles colocalized at QTLs governing this major yield component and domestication trait is thus imperative for their broader effective practical applicability in marker-aided genetic improvement of chickpea.

Significant progress has been made to decipher the complex genetic inheritance characteristics and molecular genetic dissection of flowering time trait in chickpea (Anbessa et al., 2006; Cobos et al., 2007; Pierre et al., 2008, 2011; Aryamanesh et al., 2010; Zhang et al., 2013). This involves identification of four different major early flowering (efl) gene loci/allelic variants [efl1, efl2/ppd (photoperiod), efl3 and efl4] controlling varied flowering time trait adaptation characteristics in multiple chickpea accessions (Hegde, 2010; Gaur et al., 2014; Weller and Martínez, 2015). Additionally, this includes colocalization of various known flowering time gene homologs [like Efl1, Efl2, $L F Y$ (LEAFY) and FT (flowering time) gene families] within the low-resolution major flowering time QTL regions mapped on chickpea chromosomes (Cho et al., 2002; Anbessa et al., 2006; Lichtenzveig et al., 2006; Cobos et al., 2007, 2009; Aryamanesh et al., 2010; Hossain et al., 2010; Rehman et al., 2011; Vadez et al., 2012; Jamalabadi et al., 2013; Varshney et al., 2014).

Substantial efforts have also been made to understand the complex gene regulatory networks and transcriptional modules governing flower development in a desi chickpea accession (ICC 4958) through NGS (next-generation sequencing)-based global transcriptome sequencing strategy (Singh et al., 2013). The deployment of these differentially expressed candidate genederived SNPs in association mapping and their subsequent integration with GWAS (genome-wide association study), high-resolution QTL mapping, differential transcript profiling, molecular haplotyping have delineated tissue/stage (flower bud/flower)-specific differentially regulated potential candidate genes underlying major QTLs regulating flowering time at a whole genome level in chickpea (Das et al., 2015b; Upadhyaya et al., 2015). Until yet, none of these identified genes harboring major flowering time QTLs have been validated in multiple genetic backgrounds (mapping populations) and identified through map-based cloning that could be employed for markeraided genetic enhancement of chickpea. This could be restrained due to low marker genetic polymorphism particularly between parents of multiple intra-/inter-specific mapping populations along with limited accessibility of large size mapping populations and high-density genetic linkage maps of chickpea. An alternative genome-wide approach is thus essential for quick identification and molecular mapping (fine-mapping/map-based isolation) of high-resolution flowering time QTLs/genes in order to drive genomics-led crop improvement in chickpea.

For genetic mapping of major flowering time QTLs, conventional QTL mapping approach that primarily involves genotyping of large-scale SSR (simple sequence repeat) and SNP (single nucleotide polymorphism) markers among mapping individuals of diverse inter-/intra-specific populations is found much expedient in chickpea (Anbessa et al., 2006; Lichtenzveig et al., 2006; Cobos et al., 2007, 2009; Aryamanesh et al., 2010; Hossain et al., 2010; Gowda et al., 2011; Rehman et al., 2011; Vadez et al., 2012; Jamalabadi et al., 2013; Stephens et al., 2014; Varshney et al., 2014). This approach essentially identified a diverse array of low-resolution longer marker confidence interval spanning major QTLs associated with chickpea flowering and maturation time (Cho et al., 2002; Anbessa et al., 2006; Lichtenzveig et al., 2006; Cobos et al., 2007, 2009; Aryamanesh et al., 2010; Hossain et al., 2010; Rehman et al., 2011; Vadez et al., 2012; Jamalabadi et al., 2013; Varshney et al., 2014).

The freely accessible draft genome sequences are found much proficient to accelerate genome and transcriptome resequencing of diverse desi, kabuli and wild accessions that are most commonly utilized as parents for generating diverse intra- and inter-specific mapping populations of chickpea (Jain et al., 2013; Varshney et al., 2013; Parween et al., 2015). Aside genomic resources, multiple genetic resources including advanced generation recombinant inbred lines (RILs) and backcross mapping populations as well as core/mini-core germplasm accessions exhibiting a broader range of phenotypic variation for flowering time trait are now available in chickpea (Upadhyaya et al., 2001, 2008; Gaur et al., 2014). All these available genetic and genomic resources essentially have assisted in utilization of a high-throughput NGS-based QTL-seq strategy vis-à-vis a commonly adopted traditional QTL mapping approach for fast genome-wide scanning and genetic mapping of major QTLs controlling various quantitative agronomic traits (for instance, 100-seed weight, pod number and root/total plant dry weight ratio) in chickpea (Das et al., 2015a, 2016; Singh et al., 2016).

To complement this, a multiple QTL-seq assay that relies on QTL-seq analysis in multiple mapping populations generated by inter-crossing of common parental accessions, has been 
developed currently as a most promising genome-wide strategy for QTL mapping at a high-resolution scale (Das et al., 2016). Essentially, multiple QTL-seq involves whole genome NGS resequencing of DNA bulks (exhibiting two utmost contrasting phenotypic traits) constituted from homozygous individuals of multiple mapping populations comprising at least single common parent. This approach is found most promising based on its potential to validate QTL-seq-derived major QTLs identified from individual preliminary as well as advanced generation intra-/inter-specific mapping population in multiple mapping populations of diverse genetic backgrounds. Moreover, utility of this approach is clearly evident from its efficacy to narrow-down each QTL-seq originated sizeable long QTL genomic intervals into functionally relevant potential candidate genes governing important agronomic traits (for instance, pod number) in chickpea (Das et al., 2016).

Considering usefulness and broader practical applicability, multiple QTL-seq assay can be employed for rapid genomewide scanning and fine-mapping (positional cloning) of traitlinked major genes and natural allelic-variants colocalized at robust QTLs (well-validated in multiple mapping populations) in chickpea with minimal resource expenses. This will collectively enrich our understanding on complex genetic architecture and evolutionary pattern influencing flowering time quantitative trait variation during domestication of chickpea in order to expedite its genomics-assisted crop improvement. In view of afore-mentioned possibilities, a multiple QTL-seq strategy was employed in two inter- and intra-specific RIL (recombinant inbred lines) mapping populations- (C. arietinum desi accession ICC $4958 \times C$. reticulatum wild accession ICC 17163) and (ICC $4958 \times$ C. arietinum kabuli accession ICC 8261)- at a genome-wide scale to delineate major genomic (gene) regions and novel natural allelic variants underlying the QTLs associated with flowering time in chickpea.

\section{MATERIALS AND METHODS}

\section{Development and Phenotyping of RIL Mapping Populations for Flowering Time}

Two inter- and intra-specific $F_{9}$ RIL mapping populations- (ICC $4958 \times$ ICC 17163, population size: 260 ) and (ICC $4958 \times$ ICC $8261,204)$ - with contrasting flowering time trait were developed by single seed descent method. As per field phenotyping at International Crops Research Institute for the Semi-Arid Tropics (ICRISAT), ICC 4958 (traditional cultivar/landrace, originated from India) is an early flowering chickpea accession with DTF (days to $50 \%$ flowering time) of 43 days. In contrast, ICC 17163 (wild accession) and ICC 8261 (traditional cultivar/landrace) originated from Turkey are late flowering chickpea accessions with DTF of 85 and 61 days, respectively. The desi chickpea accession ICC 4958 was considered as a common parent for both mapping populations generated.

For phenotyping, the mapping individuals and parents of both RIL populations were grown and phenotyped in the field as per RCBD (randomized complete block design) with two replications at two diverse eco-geographical regions [(ICRISAT,
Patancheru, Hyderabad: latitude $17^{\circ} 3^{\prime}$ N/longitude $77^{\circ} 2^{\prime} \mathrm{E}$ from October to February) and (National Institute of Plant Genome Research (NIPGR), New Delhi: $28^{\circ} 4^{\prime}$ N $/ 77^{\circ} 2^{\prime}$ E from November to March)] of India for two successive years (2013 and 2014) during crop growing season. In addition, these parents and RIL individuals were grown in the greenhouse to determine the flowering time response of these mapping individuals under both long- and short-day conditions at $22 \pm 2^{0} \mathrm{C}$ following Upadhyaya et al. (2015). Ten to fifteen representative plants were screened from each mapping individual and parental accession of two RIL populations, and DTF of each individual/accession was calculated as per Upadhyaya et al. (2015). The homogeneity of RIL mapping populations across two locations/years as well as major parameters contributing to genetic inheritance characteristics such as frequency distribution, CV (coefficient of variation), $\mathrm{H}^{2}$ (broad-sense heritability) of DTF trait among RIL individuals were determined as per Bajaj et al. (2015b). To evaluate the genetic inheritance pattern of flowering time trait, the interactions of mapping individuals/parents $(G)$ with their phenotyping environments (E; like years and locations) were calculated using ANOVA (analysis of variance).

\section{Whole Genome Resequencing and Multiple QTL-Seq Analysis}

We selected 10 of each early and late flowering homozygous mapping individuals belonging to two extreme ends of DTF normal frequency distribution curve from each of the two RIL populations of ICC $4958 \times$ ICC 17163 and ICC $4958 \times$ ICC 8261 for QTL-seq study. Prior to inclusion of these selected 20 RIL mapping individuals in QTL-seq analysis, the homozygous genetic constitution of these individuals from both RIL populations for either of the early and late flowering trait was assured using their DTF field phenotyping data and genomewide SSR markers-based genotyping information as per Das et al. (2015a, 2016).

The genomic DNA was isolated from constituted DNA bulks- early days to $50 \%$ flowering time bulk (EDTFB) and late days to $50 \%$ flowering time bulk (LDTFB) as well as parents of mapping populations using QIAGEN DNeasy kit (QIAGEN, United States) following manufacturer's instructions. The quantity and quality of isolated genomic DNA was ensured by Qubit 2.0 Fluorometer (Invitrogen Life Technologies, United States) and Bioanalyzer 2100 (Agilent Technologies, United States), respectively. About $1 \mu \mathrm{g}$ of high-quality genomic DNA of each sample was utilized for library preparation using Illumina TruSeq DNA PCR-Free Library Preparation Kit according to the manufacturer's protocol. The libraries were processed for paired-end sequencing (100-nucleotide long reads) using Illumina HiSeq2000 platform (Illumina Technologies, United States) and raw sequence data were filtered through standard Illumina pipeline. The FASTQ sequences were further processed through NGS QC Toolkit v2.3 (Patel and Jain, 2012) to remove low-quality including primer/adaptor contaminated sequence reads. The filtered reads with a minimum phred Q-score of 30 across $>95 \%$ of nucleotide sequence were considered as high-quality. 
Recently, a whole genome high-quality sequence assembly, including large size (510.9 Mb) chromosome pseudomolecule (334 Mb) and scaffolds of desi (ICC 4958) chickpea genome are freely available in public domain (Parween et al., 2015). Accordingly, a desi chickpea accession ICC 4958 for which the genome sequence is available was utilized as one of the common parent in two RIL mapping populations developed for our QTL-seq analysis. Therefore, we preferably utilized the latest released desi reference genome sequence as an anchor to mine resequencing-based SNPs from mapping parents and bulks for QTL-seq study at a whole genome level in chickpea.

High-quality sequence reads generated from parental accessions and bulks (EDTFB and LDTFB) were mapped onto reference desi chickpea genome using BWA with default parameters (Parween et al., 2015). Consequently, the uniquely mapped sequence reads were normalized in accordance with read coverage-depth among mapping parents and RIL individuals forming EDTFB and LDTFB bulks (Supplementary Table $\mathrm{S} 1$ ). The mined homozygous high-quality SNPs (minimum sequencing read-depth 10 with mean base quality $\geq 20$ ) exhibiting differentiation between parents as well as between EDTFB and LDTFB were structurally and functionally annotated with respect to reference desi chickpea genome following Kujur et al. $(2015 \mathrm{a}, \mathrm{b}, \mathrm{c})$. As per the earlier defined recommended parameters of Takagi et al. (2013), Lu et al. (2014), and Das et al. (2015a, 2016), SNP-index and $\Delta$ (SNP-index)-led QTL-seq assay was employed in two RIL mapping populations individually to identify major DF QTLs in chickpea. The subtraction of SNP-index (percentage of SNPs-supporting sequence reads completely different from reference desi genome) between EDTFB and LDTFB was measured as $\Delta$ (SNP-index). Following the representation of genomic fragments obtained from ICC 4958 (early DTF) and ICC 17163/ICC 8261 (late DTF) in entire genome sequences, the SNP-index was calculated as " 0 " and " 1 ," respectively. The major genomic regions underlying QTL-seq derived DTF QTLs were ascertained by $\Delta$ (SNP-index) which is altogether different from 0 at a 99\% significance level and thereby, considered to be highly significant QTLs governing flowering time in chickpea. A $10 \mathrm{Mb}$ window-size and $1 \mathrm{~kb}$ increment sliding window approach was used to evaluate the mean distribution of $\Delta$ (SNP-index) of SNPs physically mapped across chromosomes in a target genomic interval. The SNP-index plots of EDTFB and LDTFB for two individual RIL mapping populations and null hypothesis statistical confidence intervals of $\Delta$ (SNP-index) were obtained to determine the accuracy and validity of QTL-seq derived QTLs following Takagi et al. (2013), Lu et al. (2014), and Das et al. (2015a, 2016).

\section{Natural Allelic Diversity in Flowering Genes}

The novel natural SNP allelic variants of flowering timeassociated candidate genes underlying major DTF QTLs validated by multiple QTL-seq assay, were genotyped using the genomic DNA of 172 including 93 cultivated (39 desi and 53 kabuli accessions) and 79 wild chickpea accessions
[C. reticulatum (14 accessions), C. echinospermum (8), C. judaicum (22), C. bijugum (19) and C. pinnatifidum (15) and C. microphyllum (1); Bajaj et al. (2015a)] through Sequenom MALDI-TOF MassARRAY ${ }^{1}$ as per Saxena et al. (2014a,b). The SNP allelic genotyping data generated among chickpea accessions were analyzed with TASSEL v5.0 (100-kb nonoverlapping sliding window) to estimate the various nucleotide diversity parameters ( $\theta \pi$ and Tajima's D) following Bajaj et al. (2015a) and Kujur et al. (2015a). For association analysis, the genotyping data of SNPs derived from flowering time-associated genes was integrated with DTF field and greenhouse-based phenotyping information, population structure ancestry coefficient (Q-matrix), kinship-matrix (K) and principal component analysis (PCA; P) data of 172 accessions following the detailed methods as described by Upadhyaya et al. (2015) to determine the SNP allele effect on early and late flowering time differentiation in chickpea.

\section{RESULTS}

\section{Genetic Inheritance Pattern of Flowering Time in Mapping Populations}

A significant difference of DTF trait was observed on phenotyping in field at two diverse geographical locations and in green house (long- and short-day photoperiod conditions) for 2 years. This varied from 25.8 to 99.5 days with 47.1 to 57.8 days mean $\pm 13.5-16.1$ days standard deviation (SD) of DTF trait with $25.6-32.1 \% \mathrm{CV}$ and $79-86 \% \mathrm{H}^{2}$ among 260 individuals and parents of an inter-specific RIL mapping population [ICC 4958 (33.6-46.8 days mean $\pm 2.1-3.7$ days SD) $\times$ ICC 17163 (85.1-91.5 days mean \pm 3.3-4.1 days SD)] (Table 1). A wider phenotypic variation (varied from 25.7 to 70.9 days with 46.1 to 53.9 days mean $\pm 8.1-9.2$ days $\mathrm{SD}$ ) for DTF with $17.2-19.5 \% \mathrm{CV}$ and $79-83 \% \mathrm{H}^{2}$ was detected among 204 individuals and parents of an another intra-specific RIL mapping population [ICC 4958 (32.5-49.7 mean \pm 2.7-3.6 SD) $\times$ ICC 8261 (57.9-67.5 mean $\pm 2.8-4.1$ SD)] phenotyped similarly in field at two different geographical locations and in green house (long- and short-day photoperiod) for 2 years (Table 1). A significant $(P<0.0001)$ difference in DTF of individuals representing both RIL mapping populations grown under long- and short-day photoperiod conditions at green-house across 2 years was apparent. We observed a continuous variation-based normal frequency distribution along with a bi-directional transgressive segregation of DTF trait in these two RIL mapping populations (Figures 1A,B).

\section{NGS-Based Whole Genome Resequencing to Generate Sequences for QTL-Seq Study}

For QTL-seq study, we performed high-throughput whole genome NGS resequencing of early and late flowering parents as well as bulks- EDTFB (mean DTF: 22.7-28.6 days) and

${ }^{1}$ http://www.sequenom.com 
TABLE 1 | Diverse statistical measures-based DTF (days to 50\% flowering time) trait variation determined in two intra- and inter-specific chickpea RIL mapping populations grown in field at two diverse geographical locations of India and in greenhouse (long- and short-day conditions) for 2 years.

\begin{tabular}{|c|c|c|c|c|c|c|c|c|}
\hline \multirow[b]{2}{*}{$\begin{array}{l}\text { Mapping } \\
\text { populations }\end{array}$} & \multirow[b]{2}{*}{$\begin{array}{l}\text { Geographical } \\
\text { locations }\end{array}$} & \multirow[b]{2}{*}{ Years } & \multicolumn{2}{|c|}{ Parental accessions } & \multicolumn{3}{|c|}{$F_{9}$ RIL mapping individuals } & \multirow[b]{2}{*}{$\begin{array}{c}\text { Broad-sense } \\
\text { Heritability }\left(\mathrm{H}^{2} \%\right)\end{array}$} \\
\hline & & & $\begin{array}{c}\text { ICC } 4958 \\
\text { (Mean } \pm \text { SD; days) }\end{array}$ & $\begin{array}{c}\text { ICC } 17163 \\
\text { (Mean } \pm \text { SD; days) }\end{array}$ & $\begin{array}{l}\text { Mean } \pm \text { SD; } \\
\quad \text { (days) }\end{array}$ & $\begin{array}{l}\text { Range } \\
\text { (days) }\end{array}$ & $\begin{array}{c}\text { Coefficient of } \\
\text { variation (CV\%) }\end{array}$ & \\
\hline \multirow[t]{8}{*}{$\begin{array}{l}\text { ICC } 4958 \times \text { ICC } \\
17163\left(260 F_{9} \text { RILs }\right)\end{array}$} & $\begin{array}{l}\text { Patancheru } \\
\text { (Hyderabad)-field }\end{array}$ & 2012 & $43.0 \pm 2.5$ & $85.4 \pm 3.4$ & $52.9 \pm 15.3$ & $27.1-97.2$ & 28.9 & 85 \\
\hline & & 2013 & $43.2 \pm 2.1$ & $85.1 \pm 3.5$ & $52.7 \pm 13.5$ & 26.8-98.2 & 25.6 & 83 \\
\hline & New Delhi-field & 2012 & $42.8 \pm 2.6$ & $85.5 \pm 3.6$ & $52.1 \pm 14.7$ & $26.1-96.3$ & 28.2 & 86 \\
\hline & & 2013 & $43.1 \pm 2.8$ & $85.4 \pm 3.9$ & $53.4 \pm 13.8$ & $25.8-97.1$ & 25.8 & 85 \\
\hline & $\begin{array}{l}\text { Patancheru-green house } \\
\text { (Long-day condition) }\end{array}$ & 2012 & $47.5 \pm 3.4$ & $89.7 \pm 4.1$ & $56.1 \pm 16.1$ & $31.1-99.2$ & 28.7 & 81 \\
\hline & & 2013 & $46.8 \pm 3.7$ & $90.2 \pm 3.9$ & $57.8 \pm 15.5$ & 30.6-99.5 & 26.8 & 80 \\
\hline & $\begin{array}{l}\text { Patancheru-green house } \\
\text { (Short-day condition) }\end{array}$ & 2012 & $35.4 \pm 3.7$ & $90.7 \pm 3.7$ & $48.5 \pm 15.4$ & $22.4-89.7$ & 31.8 & 79 \\
\hline & & 2013 & $33.6 \pm 3.4$ & $91.5 \pm 3.3$ & $47.1 \pm 15.1$ & $23.1-90.1$ & 32.1 & 80 \\
\hline & & & \multicolumn{2}{|c|}{ Parental accessions } & \multicolumn{3}{|c|}{$F_{9}$ RIL mapping individuals } & \\
\hline $\begin{array}{l}\text { Mapping } \\
\text { populations }\end{array}$ & $\begin{array}{l}\text { Geographical } \\
\text { locations }\end{array}$ & Years & $\begin{array}{c}\text { ICC } 4958 \\
\text { (Mean } \pm \text { SD; days) }\end{array}$ & $\begin{array}{c}\text { ICC } 8261 \\
\text { (Mean } \pm \text { SD; days) }\end{array}$ & $\begin{array}{l}\text { Mean } \pm \text { SD; } \\
\quad \text { (days) }\end{array}$ & $\begin{array}{l}\text { Range } \\
\text { (days) }\end{array}$ & $\begin{array}{c}\text { Coefficient of } \\
\text { variation (CV\%) }\end{array}$ & $\begin{array}{c}\text { Broad-sense } \\
\text { Heritability }\left(\mathrm{H}^{2} \%\right)\end{array}$ \\
\hline \multirow[t]{8}{*}{$\begin{array}{l}\text { ICC } 4958 \times \text { ICC } \\
8261 \text { (204 F9 RILs) }\end{array}$} & $\begin{array}{l}\text { Patancheru } \\
\text { (Hyderabad)-field }\end{array}$ & 2012 & $43.1 \pm 2.7$ & $61.0 \pm 3.1$ & $46.1 \pm 8.7$ & $25.7-64.9$ & 18.9 & 83 \\
\hline & & 2013 & $43.5 \pm 2.9$ & $61.5 \pm 3.4$ & $46.5 \pm 8.9$ & 26.3-65.9 & 19.1 & 81 \\
\hline & New Delhi-field & 2012 & $43.1 \pm 3.1$ & $60.8 \pm 3.2$ & $46.7 \pm 9.1$ & $26.5-65.1$ & 19.5 & 80 \\
\hline & & 2013 & $42.8 \pm 3.3$ & $61.5 \pm 2.8$ & $46.9 \pm 8.8$ & 26.8-65.4 & 18.8 & 82 \\
\hline & $\begin{array}{l}\text { Patancheru-green house } \\
\text { (Long-day condition) }\end{array}$ & 2012 & $48.2 \pm 2.9$ & $66.4 \pm 4.1$ & $49.5 \pm 8.1$ & 29.1-70.9 & 16.4 & 80 \\
\hline & & 2013 & $49.7 \pm 3.4$ & $67.5 \pm 3.9$ & $48.9 \pm 8.4$ & 28.9-69.2 & 17.2 & 80 \\
\hline & $\begin{array}{l}\text { Patancheru-green house } \\
\text { (Short-day condition) }\end{array}$ & 2012 & $32.5 \pm 3.6$ & $58.7 \pm 3.5$ & $51.8 \pm 9.2$ & $30.5-69.5$ & 17.8 & 80 \\
\hline & & 2013 & $34.2 \pm 3.1$ & $57.9 \pm 3.8$ & $53.9 \pm 9.0$ & $31.8-70.2$ & 16.7 & 79 \\
\hline
\end{tabular}

LDTFB (63.0-95.1 days)- of two RIL mapping populations [(ICC $4958 \times$ ICC 17163) and (ICC $4958 \times$ ICC 8261)]. Considering the significant effect of long- and short-day photoperiod on DTF response in two RIL mapping populations across 2 years at green house, early and late flowering bulks- EDTFB (mean DTF: 25.3-30.1) and LDTFB (69.9-94.6) constituted from two RIL mapping populations were made at these two different photoperiod conditions separately and sequenced at a genomewide scale for QTL-seq study. This produced 173.8 million high-quality average sequence reads (ranged from 167.4 to 181.4 million reads) with a $\sim 30$-fold sequencing-depth coverage. The sequencing data generated in the present study were submitted to NCBI-sequence read archive (SRA) database ${ }^{2}$ with accession number SRR2229140 for unrestricted public access. About 86.5 to $90.1 \%$ sequence reads of these were mapped to unique physical locations of reference desi genome with a $73.6 \%$ mean coverage (Supplementary Table S1). To reduce the potential bias of readdepth in samples, the uniquely mapped sequence reads obtained from parents and bulks (EDTFB and LDTFB) of two RIL mapping populations were normalized in accordance with read coverage-depth. We measured the overall mapping efficiency of

${ }^{2}$ http://www.ncbi.nlm.nih.gov/sra non-redundant uniquely mapped sequence reads individually in mapping parents and bulks based on their sequencing-depth coverage (fold) as well as genome coverage (\%) (Supplementary Table S1). This covered 22.4 -fold mean sequencing depth including $73.6 \%(544.7 \mathrm{Mb})$ of desi chickpea genome (estimated genome size $\sim 740 \mathrm{Mb}$ ). For QTL-seq analysis, we compared the individual normalized sequence reads generated from mapping parents and bulks (EDTFB and LDTFB) with that of reference desi genomic sequences including pseudomolecules to discover homozygous high-quality SNPs.

\section{Molecular Mapping of QTL-Seq Driven Major DF QTLs in a Mapping Population of ICC 4958 x ICC 17163}

We discovered 1635117 SNPs (with an average map-density of $0.20 \mathrm{~kb}$ ) revealing polymorphism between early (ICC 4958 and EDTFB) and late (ICC 17163 and LDTFB) flowering mapping parents and bulks according to their congruent physical positions (bp) on the reference pseudomolecule of desi genome (Table 2 and Supplementary Tables S2, S3). We measured the SNP-index of all individual SNPs exhibiting differentiation between early (ICC 4958 and EDTFB) and late (ICC 17163 and LDTFB) 

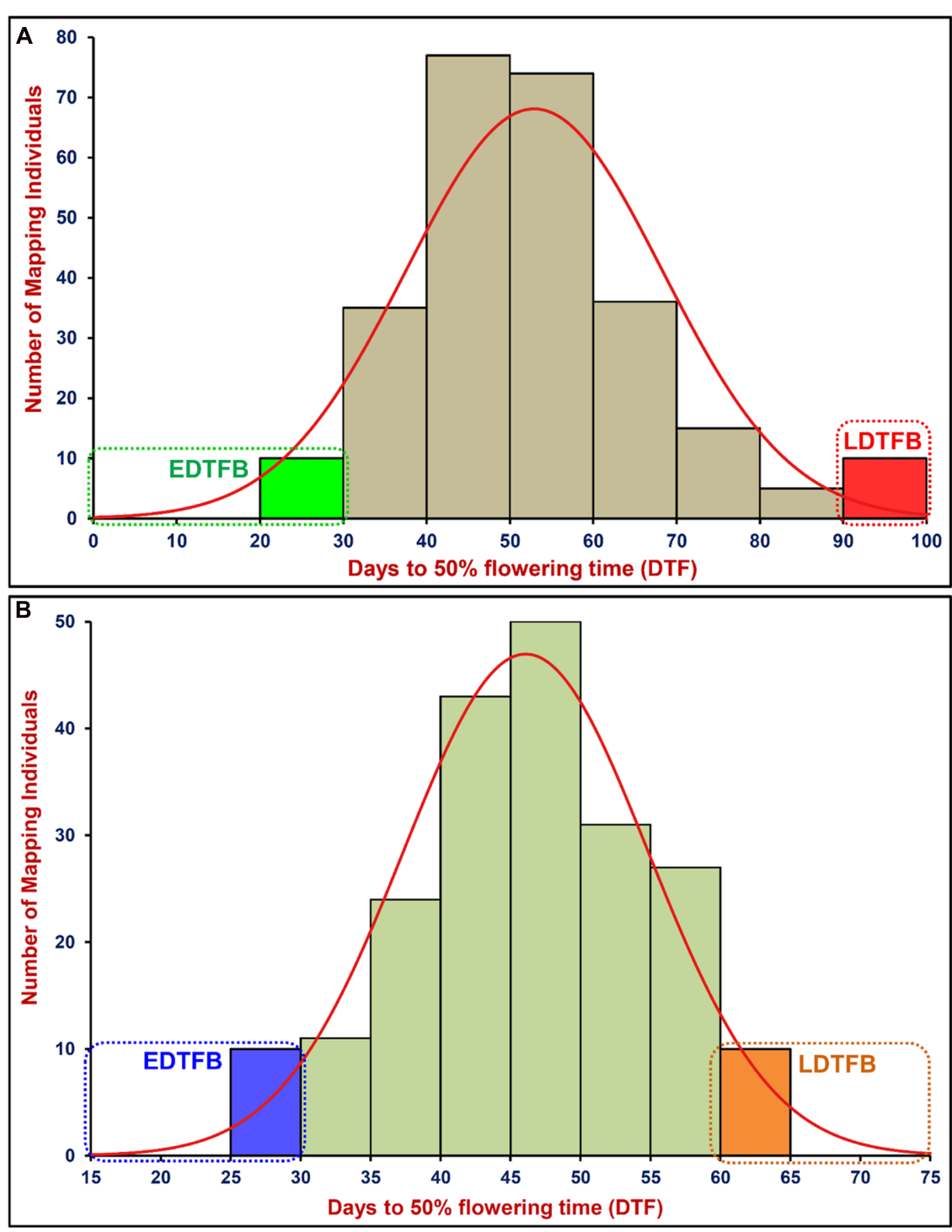

FIGURE 1 | Frequency distribution of mean days to 50\% flowering time (DTF) trait variation measured among 260 and 204 mapping individuals and parents of two Fg inter-iintra-specific RIL populations of ICC 4958 × ICC 17163 (A) and ICC 4958 × ICC 8261 (B), respectively. These were grown and phenotyped in field at two different geographical locations and green house (long- and short-day photoperiod) for 2 years. EDTFB/LDTFB: early/late days to $50 \%$ flowering time bulk.

flowering mapping parents and bulks, and plotted these SNPindex against chromosomes of reference genome. A 1-kb sliding window approach was employed to measure the mean SNP-index individually within a $10-\mathrm{Mb}$ target genomic interval. Further, the $\Delta$ (SNP-index) was calculated by integrating the SNP-index of EDTFB and LDTFB, which were plotted across the genomic locations $(\mathrm{Mb})$ of reference genome (Figure $2 \mathrm{~A}$ ).

We identified two major genomic regions (Caq ${ }^{\mathrm{a}} D T F 4.1$ : 46023168 to 46780835 bp and Caq ${ }^{\mathrm{a} D T F 4.2: ~} 26100745$ to 28089632 bp) on chromosome 4 demonstrating the mean SNPindex of $\geq 0.8$ in EDTFB and $\leq 0.2$ in LDTFB in accordance with the SNP-index measurement criteria defined in QTL-seq analysis (Takagi et al., 2013; Lu et al., 2014; Das et al., 2015a, 2016; Figures 2A, 3A). The comprehensive analysis of these selected DTF QTL genomic regions indicated the presence of majority of the SNP alleles derived from early (ICC 4958) and late (ICC 17163) flowering mapping parents in the early and late flowering mapping individuals composing the EDTFB and LDTFB bulks, respectively. Summarily, the QTL-seq assay in an inter-specific mapping population (ICC $4958 \times$ ICC 17163) assured the occurrences of two major DTF QTLs- Caq ${ }^{\mathrm{a}} D T F 4.1$ and $\mathrm{Caq}^{\mathrm{a} D T F 4.2-}$ at the $1.99 \mathrm{Mb}$ [26100745 (SNP_1A) to 28089632 (SNP_2A) bp with a $\Delta$ (SNP-index): 0.8] and 757.7 $\mathrm{kb}$ [46023168 (SNP_3A) to 46780835 (SNP_4A) bp with a $\Delta$ (SNP-index): 0.9] genomic intervals, respectively, on chickpea chromosome 4 (Figure 3A).

The detailed structural annotation of 16397 and 2542

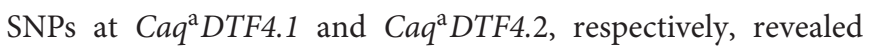


TABLE 2 | Genomic distribution of SNPs physically mapped on eight chromosomes of desi chickpea genome.

\begin{tabular}{|c|c|c|c|c|c|}
\hline \multirow[b]{2}{*}{ Chromosomes } & \multirow[b]{2}{*}{$\begin{array}{l}\text { Size (Mb) of desi chromosomes } \\
\text { (pseudomolecules) }\end{array}$} & \multicolumn{2}{|c|}{ Number $(\%)$ of SNPs mapped } & \multicolumn{2}{|c|}{ Average map density (kb) } \\
\hline & & $\begin{array}{c}\text { Desi (ICC 4958) vs. } \\
\text { Wild (ICC 17163) }\end{array}$ & $\begin{array}{c}\text { Desi (ICC 4958) vs. } \\
\text { Kabuli (CDC Frontier) }\end{array}$ & $\begin{array}{c}\text { Desi (ICC 4958) vs. } \\
\text { Wild (ICC 17163) }\end{array}$ & $\begin{array}{l}\text { Desi (ICC 4958) vs. } \\
\text { Kabuli (CDC Frontier) }\end{array}$ \\
\hline Ca_Desi_Chr01 & 39.9 & $213381(13.1)$ & $96877(16.4)$ & 0.19 & 0.41 \\
\hline Ca_Desi_ChrO2 & 33.2 & $170028(10.4)$ & $46869(7.9)$ & 0.20 & 0.71 \\
\hline Ca_Desi_Chr03 & 42.3 & 211478 (12.9) & $43852(7.4)$ & 0.20 & 0.96 \\
\hline Ca_Desi_ChrO4 & 55.0 & $298242(18.2)$ & $208734(35.2)$ & 0.18 & 0.26 \\
\hline Ca_Desi_Chr05 & 45.8 & $224449(13.7)$ & 40685 (6.9) & 0.20 & 1.13 \\
\hline Ca_Desi_Chr06 & 54.8 & 264837 (16.2) & $67588(11.4)$ & 0.21 & 0.81 \\
\hline Ca_Desi_ChrO7 & 45.3 & $174065(10.7)$ & 72792 (12.3) & 0.26 & 0.62 \\
\hline Ca_Desi_Chr08 & 17.7 & 78637 (4.8) & $15089(2.5)$ & 0.23 & 1.17 \\
\hline Total & 334 & 1635117 & 592486 & 0.20 & 0.56 \\
\hline
\end{tabular}

the occurrence of 36.4 to $50 \%$ of SNPs in the genes and remaining in the intergenic regions (Supplementary Table S4). The gene-derived SNPs comprised of highest and lowest proportion of $72.7-73.5 \%$ and $1.1-1.3 \%$ SNPs in the DRRs (downstream regulatory regions) and URRs (upstream regulatory regions), respectively. The coding SNPs included the 45.8$54.5 \%$ synonymous and $45.5-54.2 \%$ non-synonymous (missense and nonsense) SNPs (Supplementary Table S4). The allelic variants of SNPs covering these major DTF QTLs (Caq ${ }^{\mathrm{a} D T F 4.1}$ and $\mathrm{Caq}^{\mathrm{a}} \mathrm{DTF}$ 4.2) were further validated by resequencing of PCR fragments amplified from the parents (ICC 4958 and ICC 17163) and mapping individuals forming the EDTFB and LDTFB bulks. Accordingly, two major DTF QTLs were detected on similar aforesaid physical positions of chromosome 4 by the QTL-seq analysis of early- and late-flowering bulks (EDTFB and LDTFB) constituted from a RIL mapping population (ICC $4958 \times$ ICC 17163) using the long- and shortday photoperiod-based greenhouse DTF phenotyping data of chickpea.

\section{Molecular Mapping of QTL-Seq Driven Major DF QTLs in a Mapping Population of ICC 4958 x ICC 8261}

A total of 592486 SNPs (with a mean map-density of 0.56 $\mathrm{kb}$ ) were found polymorphic between early (ICC 4958 and EDTFB) and late (ICC 8261 and LDTFB) flowering mapping parents and bulks as per their congruent physical locations (bp) on the reference desi genome (pseudomolecule) (Table 2 and Supplementary Tables S2, S3). These genome resequencing-led SNPs were subsequently utilized for QTL-seq analysis.

The SNP-index of individual SNPs exhibiting differentiation between early (ICC 4958 and EDTFB) and late (ICC 8261 and LDTFB) flowering mapping parents and bulks was estimated. The mean SNP-index (within a 1-kb sliding window and $10 \mathrm{Mb}$ genomic interval) as well as $\Delta$ (SNP-index) of EDTFB and LDTFB were measured and further plotted across chromosomes as per aforesaid methods (Figure 2B). This essentially detected two major genomic regions (Caq ${ }^{\mathrm{b}}$ DTF4.1: 45600294 to 46991993 bp and Caq ${ }^{\mathrm{b} D T F 4.2:} 26500027$ to $27407090 \mathrm{bp}$ ) on chromosome 4 revealing the mean SNP-index of $\geq 0.8$ in EDTFB and $\leq 0.2$ in LDTFB (Figures $2 \mathbf{B}, 3 \mathbf{3}, \mathbf{D}$ ). The accuracy of these major genomic regions underlying DTF QTLs was ascertained by a valid $99 \% \Delta$ (SNP-index) significance level. The comprehensive analysis of these DTF QTL genomic regions inferred the occurrence of majority of the SNP alleles derived from parents (ICC 4958 and ICC 8261) in early and late flowering mapping individuals forming the EDTFB and LDTFB bulks, respectively. Overall, the QTL-seq in an intra-specific mapping population (ICC $4958 \times$ ICC 8261) identified two major DTF QTLs- Caq ${ }^{\mathrm{b}}$ DTF4.1 and Caq ${ }^{\mathrm{b}}$ DTF4.2- at the $907.1 \mathrm{~kb}[26500027$ (SNP_1B) to 27407090 (SNP_2B) bp with a $\Delta$ (SNP-index): 0.9] and $1.39 \mathrm{Mb}$ [45600294 (SNP_3B) to 46991993 (SNP_4B) bp with a $\Delta$ (SNP-index): 0.8 ] genomic intervals, respectively, on chickpea chromosome 4 (Figure 3B).

The detailed structural annotation of 7302 and 3177 SNPs at $C a q^{\mathrm{b} D T F 4.1}$ and $C a q^{\mathrm{b} D T F 4.2,}$ respectively, revealed the occurrence of 32.5 to $49.1 \%$ of SNPs in the genes and rest in the intergenic regions (Supplementary Table S4). The gene-derived SNPs included highest and lowest proportion of $73.8-74.6 \%$ and $1.2-1.5 \%$ SNPs in the DRRs and URRs, respectively. The coding SNPs included the $52.1-54.7 \%$ synonymous and 45.3-47.9\% non-synonymous (missense and nonsense) SNPs (Supplementary Table S4). The allelic variants of SNPs covering the QTL-seq led major DTF QTLs (Caq ${ }^{\mathrm{b}}$ DF4.1 and Caq ${ }^{\mathrm{b}}$ DF4.2) were validated by resequencing of PCR fragments amplified from the parents (ICC 4958 and ICC 8261) and mapping individuals composing the EDTFB and LDTFB bulks. Like-wise, we detected two major DTF QTLs on similar aforementioned physical positions of chromosome 4 by the QTL-seq analysis of EDTFB and LDTFB bulks constituted from a RIL mapping population (ICC $4958 \times$ ICC 8261) using the long- and shortday photoperiod-based greenhouse DTF phenotyping data of chickpea.

\section{Multiple QTL-Seq Rapidly Delineates Candidate Genes and Natural Allelic Variants Regulating Flowering Time in Chickpea}

We correlated and compared the four major genomic regions underlying DTF QTLs (Caq ${ }^{\mathrm{a} D T F 4.1, C a q^{\mathrm{a}} D T F 4.2, C a q^{\mathrm{b}} D T F 4.1}$ 

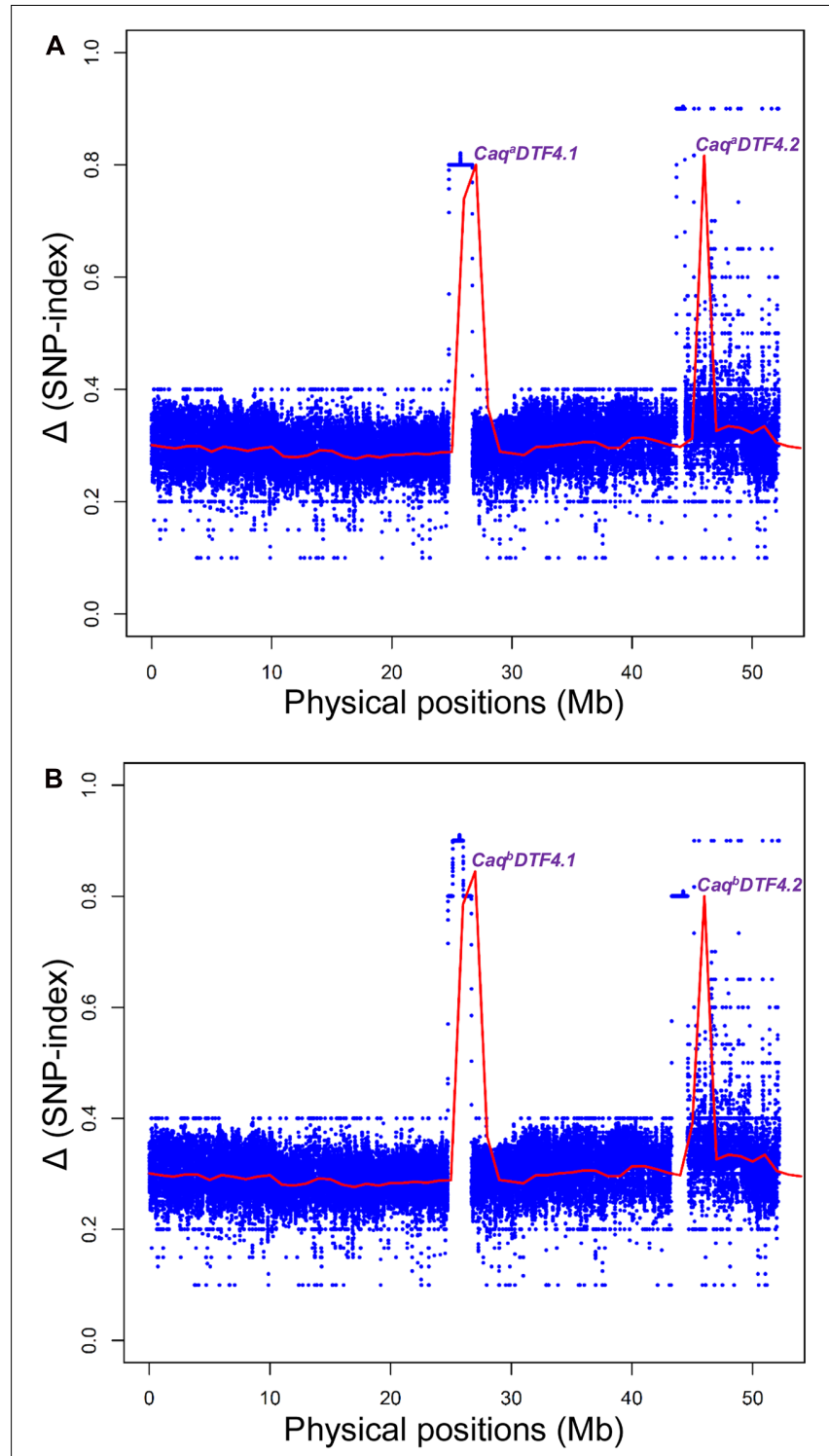

FIGURE 2 | Graphs depicting the $\Delta$ (SNP-index) of EDTFB (early days to $50 \%$ flowering time bulk) and LDFB (late days to $50 \%$ flowering time bulk) obtained from two inter-/intra-specific RIL mapping populations [A: (ICC $4958 \times$ ICC 17163) and B: (ICC $4958 \times$ ICC 8261)] using multiple QTL-seq assay. The $X$-axis specifies the physical locations (Mb) of desi chickpea chromosome 4. The $Y$-axis designates the SNP-index that was measured in accordance with $10 \mathrm{Mb}$ physical interval and $1 \mathrm{~kb}$ increment sliding window approach. The null hypothesis-based statistical confidence intervals (significance level at $P<0.001$ ) (Takagi et al., 2013; Das et al., 2015a) were used to plot the $\Delta$ (SNP-index) which identified two major genomic regions underlying DTF QTLS

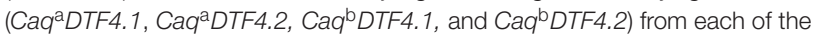
two mapping populations. These major DTF QTLs were defined based on the confidence of significant $\Delta($ SNP-index $)>0.5(P<0.001)$ and parameter of SNP-index near to 1 and 0 in EDTFB and LDTFB, respectively.
$757.7 \mathrm{~kb}$ [46023168 (SNP_3A) to 46780835 (SNP_4A) bp] and $907.1 \mathrm{~kb}$ [26500027 (SNP_1B) to 27407090 (SNP_2B) bp] harboring the major DTF QTLs were detected on chromosome 4 (Figures 3A,B). Our comprehensive multiple QTL-seq analysis in two inter-/intra-specific RIL mapping populations ascertained the validity of novel natural allelic variants-containing similar efl 1 and GI genes with a highest $\Delta$ (SNP-index) of 1.0 at $C a q^{\mathrm{a}} D T F 4.2$ and $C a q^{\mathrm{b}} D T F 4.1$ QTL regions governing flowering time in chickpea. Henceforth, these strong flowering time-associated efl1 and GI genes localized at a major DTF QTL interval $\left(C a q^{\mathrm{a}} D T F 4.2\right.$ and $C a q^{\mathrm{b}}$ DTF4.1) were considered as the potential candidates for flowering time regulation in chickpea. This essentially identified two upstream regulatory [46630632 (G/A) and $46630495(\mathrm{C} / \mathrm{T})$ $\mathrm{bp}$ ] and one non-synonymous [Asparagine (AAT) to Serine (AGT)] coding [46618224 (A/G) bp] SNP allelic variants from a efl 1 desi gene (Ca11444) as well as two synonymous coding [27092669 (G/A) bp] and downstream regulatory [27096726 $(\mathrm{C} / \mathrm{T}) \mathrm{bp}$ ] SNP alleles from a GI desi gene (Ca10198) regulating flowering time in chickpea (Figures $\mathbf{3 A}, \mathbf{B}$ and Supplementary Figure S1).

\section{Natural Allelic Diversity-Led Domestication Pattern in Flowering Time Genes}

The novel SNP allelic variants discovered from the coding (synonymous and non-synonymous) and non-coding regulatory sequence regions of two flowering genes, efl1 (117 SNPs) and GI (31) localized at two major DTF QTL regions (identified by multiple QTL-seq) were genotyped in 93 desi and kabuli cultivated and 79 wild chickpea accessions to determine their natural/functional allelic diversity-based domestication pattern based on multiple nucleotide diversity parameters $(\theta \pi$ and Tajima's D) (Supplementary Table S5). The coding and regulatory SNPs discovered from the efl1 (36-49\% phenotypic variation explained) and GI (33-42\%) flowering genes exhibited significantly higher association potential for early and late DTF differentiation among chickpea accessions (Table 3). Notably, only 9 to $12 \%$ of natural allelic variation-based functional diversity level estimated in efl1 and GI flowering genes among wild gene pool was retained and thus got preserved in cultivated chickpea. The relative mean natural allelic diversity of two flowering genes (efl 1 and GI) localized at major DTF QTL regions between cultivated and wild chickpea varied from 88 to $91 \%(\theta \pi \mathrm{Cc} / \theta \pi \mathrm{Cw})$. This was much higher than the relative mean natural allelic diversity level $(\theta \pi \mathrm{Cc} / \theta \pi \mathrm{Cw}: 61.8 \%)$ estimated by using 7116 genome-wide SNPs localized at genomic regions where no DTF QTLs were mapped.

\section{DISCUSSION}

A broader phenotypic variation coupled with bi-directional transgressive segregation (normal frequency distribution) of DTF trait among RIL individuals and parents of inter (ICC $4958 \times$ ICC 17163)- and intra (ICC $4958 \times$ ICC 8261)-specific mapping 


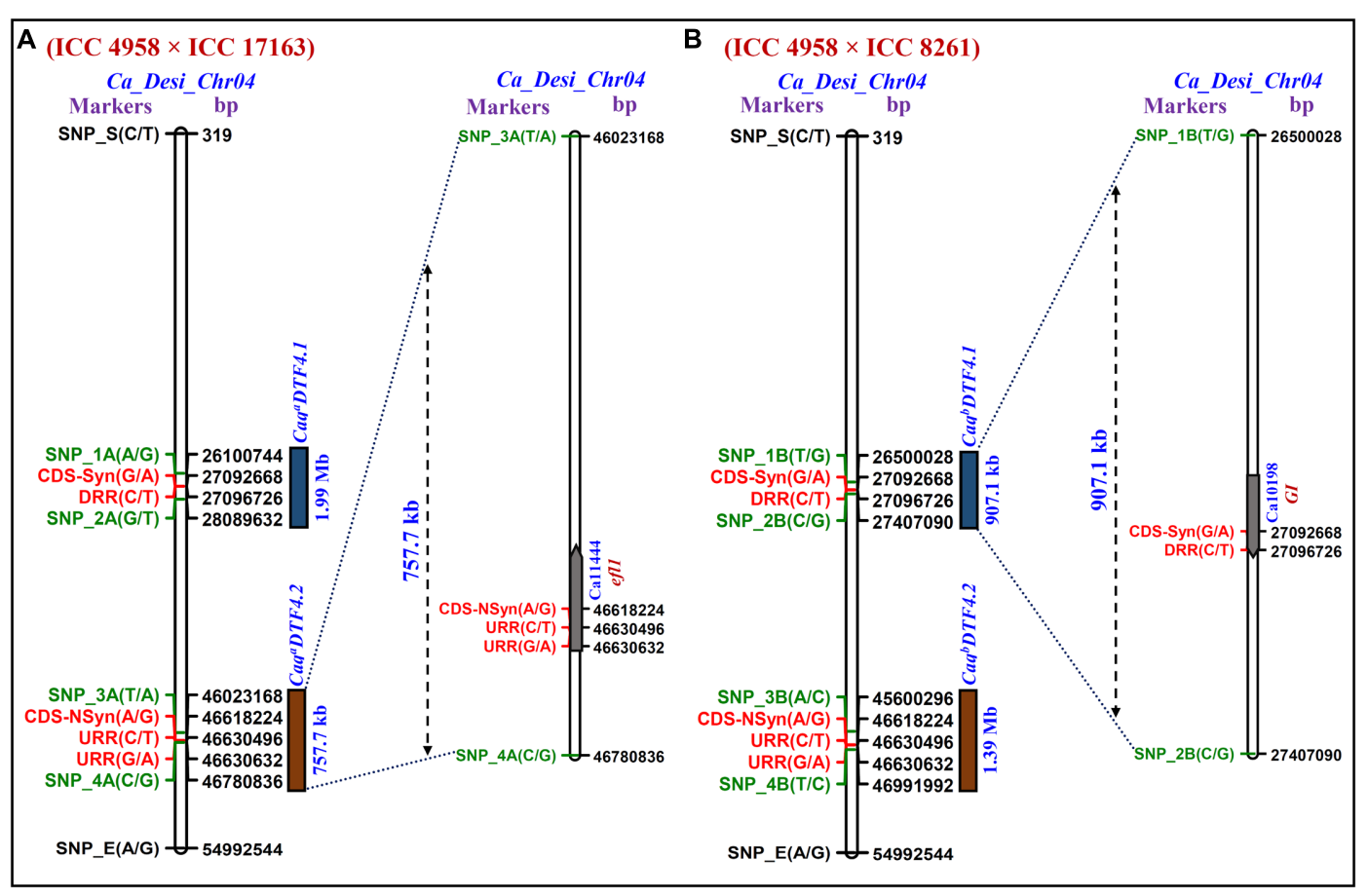

FIGURE 3 | The integration of $\Delta$ (SNP-index)-led multiple QTL-seq derived four major flowering time QTLs (Caq ${ }^{\mathrm{a}}$ DTF4.1, Caq ${ }^{\mathrm{a}}$ DTF4.2, Caq ${ }^{\mathrm{b}}$ DTF4.1, and Caq ${ }^{\text {DDTF4 }}$ 2) in two RIL mapping populations [A: (ICC $4958 \times$ ICC 17163) and B: (ICC $4958 \times$ ICC 8261)] scaled-down two longer novel major genomic regions underlying two flowering time QTLs, Caqa DTF4.1 and Caq ${ }^{\mathrm{b}}$ DTF4.2 into two smaller 757.7 [between flanking SNP markers: SNP_3A (46023168 bp) to SNP_4A (46780835 bp)] and 907.1 [SNP_1B (26500027 bp) to SNP_2B (27407090 bp)] kb sequence intervals (marked by green font), respectively, on desi chromosome 4. Consequently, based on highest $\Delta$ (SNP-index) value in these multiple QTL-seq derived DTF QTL intervals, three regulatory and synonymous/non-synonymous coding SNP allelic variants-containing two potential efl1 and Gl genes (indicated by red font) regulating flowering time were delineated in chickpea.

TABLE 3 | Gene-derived SNP alleles associated with days to 50\% flowering time (DTF) detected by association mapping in chickpea.

\begin{tabular}{|c|c|c|c|c|c|c|c|c|c|}
\hline \multirow[b]{2}{*}{ SNP IDs* } & \multirow[b]{2}{*}{$\begin{array}{c}\text { Kabuli } \\
\text { chromosomes }\end{array}$} & \multirow[b]{2}{*}{$\begin{array}{l}\text { SNP physical } \\
\text { positions (bp) }\end{array}$} & \multirow[b]{2}{*}{ SNPs } & \multirow[b]{2}{*}{$\begin{array}{c}\text { Gene } \\
\text { accession IDs }\end{array}$} & \multirow[b]{2}{*}{$\begin{array}{l}\text { Structural } \\
\text { annotation }\end{array}$} & \multirow[b]{2}{*}{$\begin{array}{l}\text { Encoded gene } \\
\text { (protein) }\end{array}$} & \multicolumn{2}{|c|}{ Association analysis } & \multirow[b]{2}{*}{$\begin{array}{c}\text { Traits } \\
\text { associatec }\end{array}$} \\
\hline & & & & & & & $P$ & $\begin{array}{l}\text { PVE } \\
\text { (\%) }\end{array}$ & \\
\hline \multirow[t]{2}{*}{ Ca_LG_446618224 } & Ca_Kabuli_Chr4 & 46618224 & $A$ & Ca11444 & $\begin{array}{l}\text { CDS (Non- } \\
\text { synonymous) }\end{array}$ & $\begin{array}{l}\text { efl1 (early } \\
\text { flowering 1) }\end{array}$ & $1.56 \times 10^{-13}$ & 36 & EDTF \\
\hline & & 46618224 & $G$ & & & & $1.43 \times 10^{-12}$ & 38 & LDTF \\
\hline \multirow[t]{2}{*}{ Ca_LG_446630495 } & Ca_Kabuli_Chr4 & 46630495 & C & Ca11444 & URR & $\begin{array}{l}\text { efl1 (early } \\
\text { flowering 1) }\end{array}$ & $1.07 \times 10^{-12}$ & 49 & EDTF \\
\hline & & 46630495 & $\mathrm{~T}$ & & & & $1.13 \times 10^{-10}$ & 47 & LDTF \\
\hline \multirow[t]{2}{*}{ Ca_LG_446630632 } & Ca_Kabuli_Chr4 & 46630632 & $G$ & Ca11444 & URR & $\begin{array}{l}\text { efl1 (early } \\
\text { flowering 1) }\end{array}$ & $1.24 \times 10^{-12}$ & 41 & EDTF \\
\hline & & 46630632 & $A$ & & & & $1.37 \times 10^{-12}$ & 40 & LDTF \\
\hline \multirow[t]{2}{*}{ Ca_LG_427092669 } & Ca_Kabuli_Chr4 & 27092669 & $G$ & Ca10198 & $\begin{array}{l}\text { CDS } \\
\text { (Synonymous) }\end{array}$ & GI (GIGANTEA) & $1.17 \times 10^{-10}$ & 35 & EDTF \\
\hline & & 27092669 & $A$ & & & & $1.22 \times 10^{-10}$ & 33 & LDTF \\
\hline \multirow[t]{2}{*}{ Ca_LG_427096726 } & Ca_Kabuli_Chr4 & 27096726 & C & Ca10198 & DRR & GI (GIGANTEA) & $1.30 \times 10^{-11}$ & 43 & EDTF \\
\hline & & 27096726 & T & & & & $1.40 \times 10^{-10}$ & 42 & LDTF \\
\hline
\end{tabular}

*Correspond to SNP IDs mentioned in Supplementary Tables S2, S3. EDTF/LDTF, early/late DTF. PVE, phenotypic variation explained.

population phenotyped in field and green house (long- and shortday) conditions at two different geographical locations/years was evident. This infers the complex genetic inheritance pattern of flowering time quantitative trait in chickpea. Therefore, genetic dissection of this complex quantitative trait employing various genomics-assisted breeding strategies is essential for genetic enhancement and to develop early flowering high seed and pod-yielding stress tolerant cultivars of chickpea during 
present scenario of climate change. To accomplish these, our study selectively employed a rapid, cost-efficient and NGS-led high-throughput multiple QTL-seq assay in two inter- and intra-specific RIL mapping population exhibiting a much wider flowering time trait variation including a higher heritability (consistent phenotypic expression) for flowering time in field and green house (long- and short-day) across two diverse geographical locations/years in order to identify major flowering time QTLs in chickpea.

The QTL-seq analysis in an inter-specific RIL mapping population (ICC $4958 \times$ ICC 17163) detected $1.99 \mathrm{Mb}$ and $757.7 \mathrm{~kb}$ two major genomic regions underlying $\mathrm{Caq}^{\mathrm{a}} \mathrm{DTF} 4.1$ and $C a q^{\mathrm{a}} D T F 4.2$ QTLs, respectively, mapped on chromosome 4 governing flowering time in chickpea. Like-wise, $907.1 \mathrm{~kb}$ and $1.39 \mathrm{Mb}$, two major genomic intervals of $\mathrm{Caq}^{\mathrm{b}}$ DTF4.1 and Caq ${ }^{\mathrm{b}}$ DTF4.2 QTLs, respectively, mapped on chromosome 4 were detected by QTL-seq analysis in an intra-specific RIL mapping population (ICC $4958 \times$ ICC 8261). These analyses altogether led to identify two consensus major short physical genomic regions of $757.7 \mathrm{~kb}$ and $907.1 \mathrm{~kb}$ harboring $C a q^{\mathrm{a}}$ DTF4.2 and Caq ${ }^{\mathrm{b}}$ DTF4.1 QTLs, respectively, on chromosome 4 of chickpea. The validation of these major DTF QTLs across two diverse intra-/inter-specific chickpea mapping population was apparent implicating the robustness of identified QTLs in regulating flowering time in chickpea. The aforesaid outcomes also inferred the efficacy of multiple QTL-seq assay to narrow-down the longer major DTF QTL intervals detected by QTL-seq in an individual mapping population into shorter major QTL regions in multiple mapping populations of chickpea. This suggests the potential utility of multiple QTL-seq over NGS-based QTL-seq assay and other conventional QTL mapping approaches in high-resolution molecular/fine mapping of major genomic regions harboring QTLs governing diverse agronomic traits including flowering time in chickpea. As per congruent physical positions (bp) on desi chromosome 4, two short interval DTF QTLs (Caq DTF4.2 and Caq ${ }^{\mathrm{b}}$ DTF4.1) revealed correspondence with the two earlier identified known major flowering time QTLs (CaqDF4.1 and CaqDF4.2) that are identified and mapped on an intra-specific high-density genetic linkage map (ICC $16374 \times$ ICC 762 ) of chickpea (Upadhyaya et al., 2015).

The comprehensive multiple QTL-seq analysis at $C a q^{\mathrm{a}} D T F 4.2$ and $C a q^{\mathrm{b}}$ DTF4.1 QTL regions detected novel natural allelic variants-containing two strong flowering time-associated efl 1 and GI genes with highest $\Delta$ (SNP-index) of 1.0 and thereby, considered as the potential candidates for flowering time regulation in chickpea. Two potential candidate genes, efl 1 and GI underlying these major QTLs (Caq ${ }^{\mathrm{a} D T F 4.2 / C a q D F 4.1}$ and Caq ${ }^{\mathrm{b}}$ DTF4.1/CaqDF4.2 detected in our present and past studies, respectively) regulating flowering time have been delineated by deploying an integrated genomics-assisted breeding strategy involving candidate gene-based trait association mapping, GWAS, QTL mapping, differential transcript expression profiling and gene-specific molecular haplotyping in chickpea (Upadhyaya et al., 2015). The potential of these identified known flowering development pathway and FT gene homologs like efl1 and GI colocalized at the major QTLs in regulating flowering time have been documented by different traditional QTL mapping studies involving diverse intra- and inter-specific mapping populations of chickpea (Cho et al., 2002; Anbessa et al., 2006; Lichtenzveig et al., 2006; Cobos et al., 2007, 2009; Radhika et al., 2007; Aryamanesh et al., 2010; Hossain et al., 2010; Gowda et al., 2011; Rehman et al., 2011; Hiremath et al., 2012; Vadez et al., 2012; Jamalabadi et al., 2013; Zhang et al., 2013; Varshney et al., 2014). Notably, functional validation and comprehensive molecular characterization of photoperiod-independent efl1 gene and photoperiod-dependent circadian-clock-related GI gene have implicated their potential involvement in regulating flowering time of legumes and Arabidopsis (Hecht et al., 2007; Liu et al., 2008; Watanabe et al., 2009, 2011, 2012; Weller et al., 2009; Kang et al., 2010; Laurie et al., 2011; Andres and Coupland, 2012; Kim et al., 2012; Pin and Nilsson, 2012; Song et al., 2013; Yamashino et al., 2013; Zhai et al., 2014; Weller and Martínez, 2015).

Despite of identifying similar flowering time efl 1 and GI genes between past and present studies, we were able to discover diverse novel flowering time-regulating non-synonymous and regulatory natural SNP allelic variants (unlike our previous study by Upadhyaya et al., 2015) from the two target efl and GI genes that are localized in the two multiple QTL-seq derived major DTF QTL regions $\left(C a q^{\mathrm{a}} D T F 4.2\right.$ and $C a q^{\mathrm{b}}$ DTF4.1) of chickpea. The detection of altogether different natural allelic variants from two similar efl 1 and GI flowering genes localized at two major DTF QTL regions between past and present studies collectively infers the population/cultivar-specific genetic inheritance pattern of complex flowering time quantitative trait in diverse genetic backgrounds of chickpea. The above clues collectively suggest the accuracy, robustness and wider practical applicability of multiple QTL-seq approach for fast genome-wide scanning and mapping of high-resolution major flowering time QTLs as well as delineation of candidate genes and novel natural alleles underlying these major QTLs governing flowering time in chickpea.

The quantitative flowering time trait is primarily governed by complex regulatory networks/pathways involving a diverse array of genes in plant species including legumes (Andres and Coupland, 2012; Song et al., 2013; Weller and Martínez, 2015). The molecular haplotyping of efl 1 and GI genes (detected by multiple QTL-seq) among diverse desi and kabuli cultivated and wild accessions has detected multiple novel natural allelic variants including haplotypes in these flowering time genes exhibiting varied potential characteristics for flowering time trait regulation and evolutionary pattern in domesticated chickpea (Upadhyaya et al., 2015). Therefore, novel functionally relevant potential molecular signatures (SNP markers, genes, QTLs and natural allelic variants) governing flowering time delineated by us employing a NGS-based high-throughput multiple QTL-seq strategy can be useful for fast genetic dissection of complex flowering time quantitative trait and eventually genomics-assisted crop improvement to develop early flowering varieties of chickpea with limited resource expenses.

Preliminary efforts have been made to understand the natural/functional allelic diversity-based domestication pattern 
of two flowering (efl1 and GI) genes localized at two major DTF QTL regions among Cicer cultivated (desi and kabuli) and wild genepools. This exhibited a significant reduction of natural/functional allelic diversity in cultivated desi and kabuli accessions from diverse geographical regions of the world as compared to annual and perennial wild accessions belonging to primary, secondary and tertiary gene pools of chickpea. However, this observed background allelic diversity reduction in cultivated than that of wild chickpea was much stronger especially at major DTF QTL regions where efl1 and GI flowering genes were mapped. This implicates that these genes were targeted by artificial selection which was further evident from their non-neutral evolution during chickpea domestication based on significant variation of Tajima's D between cultivated $(-1.12)$ and wild (0.26) accessions, respectively. Interestingly, all these natural allelic variantscontaining two potential genes localized within flowering time major QTL intervals have been commonly identified and mapped on multiple independent chickpea mapping populations by earlier and our present studies (Upadhyaya et al., 2015). These outcomes clearly reflect the extensive contribution of four sequential evolutionary bottlenecks including vernalization and strong artificial and/or natural selection pressure on these flowering time-associated natural allelic variants of two gene loci (efl1 and GI) during chickpea domestication leading toward reduction of genetic diversity in cultivated chickpea as compared to that of wild Cicer genepool (Lev-Yadun et al., 2000; Abbo et al., 2003; Berger et al., 2005; Burger et al., 2008; Toker, 2009; Meyer et al., 2012; Jain et al., 2013; Kujur et al., 2013; Varshney et al., 2013; Saxena et al., 2014a,b).

The most crucial evolutionary bottleneck, vernalization, is a vital key module of flowering time during chickpea domestication culminating into existence of currently cultivated vernalization insensitive desi and kabuli cultivars specifically from the vernalization sensitive wild ancestor $C$. reticulatum (Abbo et al., 2003, 2014; Berger et al., 2005; Burger et al., 2008; Toker, 2009). The major domestication bottlenecks integrated with artificial selection including modern breeding efforts have been constantly practiced during the chickpea genetic improvement program for developing its early flowering cultivars of high seed and pod yield. These findings collectively infer that the natural allelic variation-based functional diversity scanned in the genes might be associated with flowering time trait evolution with regard to differential domestication-led bottlenecks including vernalization response in desi and kabuli cultivated and wild chickpea during domestication. Henceforth, flowering time represents a vital component of domestication trait selected during breeding and genetics of chickpea. Moreover, the major impact of long- and short-photoperiods which are the major environmental cues for determining the flowering time including time of flower initiation and/or first flower appearance especially in photoperiod-sensitive as compared to photoperiod-insensitive chickpea accessions is well documented (Daba et al., 2016). In the present study, a significant interactions between long- and short-day photoperiods and DTF trait variation observed in individuals of two RIL mapping populations across 2 years was apparent. In spite of this concern, we were able to identify functionally relevant nonsynonymous/synonymous coding and regulatory SNP allelic variants from two flowering genes (efll and GI) localized at two major DTF QTL regions by using the long- and shortday phenotyping data of both RIL populations separately in multiple QTL-seq assay. This further infers the efficacy of strategy (multiple QTL-seq) implemented in our study to detect potential molecular signatures regulating flowering time in chickpea. It is, therefore, essential to perform a comprehensive analysis using all natural/functional allelic variants discovered and potential locus targeted by natural and/or artificial selection in two flowering genes (efll and GI) to delve deeper into the complex flowering time trait evolution and domestication in chickpea. This will be useful to understand the molecular mechanism influencing fixation of such complex flowering time quantitative trait in domesticated cultivars that are adapted to multiple agroecological regions of the world and further pave the way for genetic enhancement to develop early flowering high seed/podyielding varieties of chickpea amidst current climate change scenario.

\section{AUTHOR CONTRIBUTIONS}

$\mathrm{RS}, \mathrm{AD}$, and $\mathrm{UB}$ conducted all experiments and drafted the manuscript. HU, RK, PS, ST, and CB helped in development, advancement and phenotyping of mapping populations. AT and SP conceived and designed the study, guided data analysis and interpretation, participated in drafting and correcting the manuscript critically and gave the final approval of the version to be published. All authors have read and approved the final manuscript.

\section{ACKNOWLEDGMENT}

The financial support by the Department of Biotechnology (DBT), Government of India to NIPGR is acknowledged.

\section{SUPPLEMENTARY MATERIAL}

The Supplementary Material for this article can be found online at: http://journal.frontiersin.org/article/10.3389/fpls.2017.01105/ full\#supplementary-material. For Tables S2 and S3, see: https:// figshare.com/s/f1848022c4f3c620f1d2. 


\section{REFERENCES}

Abbo, S., Berger, J., and Turner, N. C. (2003). Evolution of cultivated chickpea: four bottlenecks limit diversity and constrain adaptation. Funct. Plant Biol. 30, 1081-1087. doi: 10.1071/FP03084

Abbo, S., Pinhasi van-Oss, R., Gopher, A., Saranga, Y., Ofner, I., and Peleg, Z. (2014). Plant domestication versus crop evolution: a conceptual framework for cereals and grain legumes. Trends Plant Sci. 19, 351-360. doi: 10.1016/j.tplants. 2013.12.002

Anbessa, Y., Warkentin, T., Vandenberg, A., and Ball, R. (2006). Inheritance of time to flowering in chickpea in a short-season temperate environments. J. Hered. 97, 55-61. doi: 10.1093/jhered/esj009

Andres, F., and Coupland, G. (2012). The genetic basis of flowering responses to seasonal cues. Nat. Rev. Genet. 13, 627-639. doi: 10.1038/nrg3291

Aryamanesh, N., Nelson, M. N., Yan, G., Clarke, H. J., and Siddique, K. H. M. (2010). Mapping a major gene for growth habit and QTLs for Ascochyta blight resistance and flowering time in a population between chickpea and Cicer reticulatum. Euphytica 173, 307-319. doi: 10.1007/s10681-009-0086-2

Bajaj, D., Das, S., Upadhyaya, H. D., Ranjan, R., Badoni, S., Kumar, V., et al. (2015a). A genome-wide combinatorial strategy dissects complex genetic architecture of seed coat color in chickpea. Front. Plant Sci. 6:979. doi: 10.3389/ fpls.2015.00979

Bajaj, D., Upadhyaya, H. D., Khan, Y., Das, S., Badoni, S., Shree, T., et al. (2015b). A combinatorial approach of comprehensive QTL-based comparative genome mapping and transcript profiling identified a seed weight-regulating candidate gene in chickpea. Sci. Rep. 5:9264. doi: 10.1038/srep09264

Berger, J. D., Buck, R., Henzell, J. M., and Turner, N. C. (2005). Evolution in the genus Cicer vernalisation response and low temperature pod set in chickpea (C. arietinum L.) and its annual wild relatives. Aust. J. Agric. Res. 56, 1191-1200. doi: 10.1071/AR05089

Burger, J. C., Champan, M. A., and Burke, J. M. (2008). Molecular insights into the evolution of crop plants. Am. J. Bot. 95, 113-122. doi: 10.3732/ajb.95. 2.113

Cho, S., Kumar, J., Shultz, J. F., Anupama, K., Tefera, F., and Muehlbauer, F. J. (2002). Mapping genes for double podding and other morphological traits in chickpea. Euphytica 125, 285-292. doi: 10.1023/A:1020872009306

Cobos, M. J., Rubio, J., Fernández-Romero, M. D., Garza, R., Moreno, M. T., Millán, T., et al. (2007). Genetic analysis of seed size, yield and days to flowering in a chickpea recombinant inbred line population derived from a kabuli $\mathrm{x}$ desi cross. Ann. Appl. Biol. 151, 33-42. doi: 10.1111/j.1744-7348.2007.00152.x

Cobos, M. J., Winter, P., Kharrat, M., Cubero, J. I., Gil, J., and Millán, T. (2009). Genetic analysis of agronomic traits in a wide cross of chickpea. Field Crops Res. 111, 130-136. doi: 10.1016/j.fcr.2008.11.006

Daba, K., Warkentin, T. D., Bueckert, R., Todd, C. D., and Tar'an, B. (2016). Determination of photoperiod-sensitive phase in chickpea (Cicer arietinum L.). Front. Plant Sci. 7:478. doi: 10.3389/fpls.2016.00478

Das, S., Singh, M., Srivastava, R., Bajaj, D., Saxena, M. S., Rana, J. C., et al. (2016). mQTL-seq delineates functionally relevant candidate gene harbouring a major QTL regulating pod number in chickpea. DNA Res. 23, 53-65. doi: 10.1093/ dnares/dsv036

Das, S., Upadhyaya, H. D., Bajaj, D., Kujur, A., Badoni, S., Laxmi, et al. (2015a). Deploying QTL-seq for rapid delineation of a potential candidate gene underlying major trait-associated QTL in chickpea. DNA Res. 22, 193-203. doi: 10.1093/dnares/dsv004

Das, S., Upadhyaya, H. D., Srivastava, R., Bajaj, D., Gowda, C. L. L., Sharma, S., et al. (2015b). Genome-wide insertion-deletion (InDel) marker discovery and genotyping for genomics-assisted breeding applications in chickpea. DNA Res. 22, 377-386. doi: 10.1093/dnares/dsv020

Gaur, P. M., Samineni, S., Tripathi, S., Varshney, R. K., and Gowda, C. L. L. (2014). Allelic relationships of flowering time genes in chickpea. Euphytica 203, 295-308. doi: 10.1007/s10681-014-1261-7

Gowda, C. L. L., Upadhyaya, H. D., Dronavalli, N., and Singh, S. (2011). Identification of large-seeded high-yielding stable kabuli chickpea germplasm lines for use in crop improvement. Crop Sci. 5, 198-209. doi: 10.2135/ cropsci2010.01.0078

Hecht, V., Knowles, C. L., Vander Schoor, J. K., Liew, L. C., Jones, S. E., Lambert, M. J., et al. (2007). Pea LATE BLOOMER1 is a GIGANTEA ortholog with roles in photoperiodic flowering, deetiolation, and transcriptional regulation of circadian clock gene homologs. Plant Physiol. 144, 648-661. doi: 10.1104/pp 107.096818

Hegde, V. S. (2010). Genetics of flowering time in chickpea in a semi-arid environment. Plant Breed. 129, 683-687. doi: 10.1111/j.1439-0523.2009.01748.x

Hiremath, P. J., Kumar, A., Penmetsa, R. V., Farmer, A., Schlueter, J. A., Chamarthi, S. K., et al. (2012). Large-scale development of cost-effective SNP marker assays for diversity assessment and genetic mapping in chickpea and comparative mapping in legumes. Plant Biotechnol. J. 10, 716-732. doi: 10.1111/j.1467-7652. 2012.00710.x

Hossain, S., Ford, R., McNeil, D. L., Pittock, C., and Pannozzo, J. F. (2010). Development of a selection tool for seed shape and QTL analysis of seed shape with other morphological traits for selective breeding in chickpea (Cicer arietinum L.). Aust. J. Crop Sci. 4, 278-288.

Jain, M., Misra, G., Patel, R. K., Priya, P., Jhanwar, S., Khan, A. W., et al. (2013). A draft genome sequence of the pulse crop chickpea (Cicer arietinum L.). Plant J. 74, 715-729. doi: 10.1111/tpj.12173

Jamalabadi, J. G., Saidi, A., Karami, E., Kharkesh, M., and Talebi, R. (2013). Molecular mapping and characterization of genes governing time to flowering, seed weight, and plant height in an intraspecific genetic linkage map of chickpea (Cicer arietinum). Biochem. Genet. 51, 387-397. doi: 10.1007/s10528-0139571-3

Kang, J., Hwang, J. U., Lee, M., Kim, Y. Y., Assmann, S. M., Martinoia, E., et al. (2010). PDR-type ABC transporter mediates cellular uptake of the phytohormone abscisic acid. Proc. Natl. Acad. Sci. U.S.A. 107, 2355-2360. doi: 10.1073/pnas.0909222107

Kashiwagi, J., Krishnamurthy, L., Gaur, P. M., Upadhyaya, H. D., Varshney, R. K., and Tobita, S. (2013). Traits of relevance to improve yield under terminal drought stress in chickpea (C. arietinum L.). Field Crops Res. 145, 88-95. doi: 10.1016/j.fcr.2013.02.011

Kim, M. Y., Shin, J. H., Kang, Y. J., Shim, S. R., and Lee, S. H. (2012). Divergence of flowering genes in soybean. J. Biosci. 37, 857-870. doi: 10.1007/s12038-0129252-0

Kujur, A., Bajaj, D., Saxena, M. S., Tripathi, S., Upadhyaya, H. D., Gowda, C. L. L., et al. (2013). Functionally relevant microsatellite markers from chickpea transcription factor genes for efficient genotyping applications and trait association mapping. DNA Res. 20, 355-374. doi: 10.1093/dnares/dst015

Kujur, A., Bajaj, D., Upadhyaya, H. D., Das, S., Ranjan, R., Shree, T., et al. (2015a). Employing genome-wide SNP discovery and genotyping strategy to extrapolate the natural allelic diversity and domestication patterns in chickpea. Front. Plant Sci. 6:162. doi: 10.3389/fpls.2015.00162

Kujur, A., Bajaj, D., Upadhyaya, H. D., Das, S., Ranjan, R., Shree, T., et al. (2015b). A genome-wide SNP scan accelerates trait-regulatory genomic loci identification in chickpea. Sci. Rep. 5:11166. doi: 10.1038/srep11166

Kujur, A., Upadhyaya, H. D., Shree, T., Bajaj, D., Das, S., Saxena, M. S., et al. (2015c). Ultra-high density intra-specific genetic linkage maps accelerate identification of functionally relevant molecular tags governing important agronomic traits in chickpea. Sci. Rep. 5:9468. doi: 10.1038/srep 09468

Kumar, A., Choudhary, A. K., Solanki, R. K., and Pratap, A. (2011). Towards marker-assisted selection in pulses: a review. Plant Breed. 130, 297-313. doi: 10.1007/s00299-017-2127-y

Laurie, R. E., Diwadkar, P., Jaudal, M., Zhang, L., Hecht, V., Wen, J., et al. (2011). The Medicago truncatula flowering locus T homologue, MtFTal, is a key regulator of flowering time. Plant Physiol. 156, 2207-2224. doi: 10.1104/pp. 111.180182

Lev-Yadun, S., Gopher, A., and Abbo, S. (2000). The cradle of agriculture. Science 288, 1602-1603. doi: 10.1126/science.288.5471.1602

Lichtenzveig, J., Bonfil, D. J., Zhang, H. B., Shtienberg, D., and Abbo, S. (2006). Mapping quantitative trait loci in chickpea associated with time to flowering and resistance to Didymella rabiei the causal agent of Ascochyta blight. Theor. Appl. Genet. 113, 1357-1369. doi: 10.1007/s00122-006-0390-3

Liu, B., Kanazawa, A., Matsumura, H., Takahashi, R., Harada, K., and Abe, J. (2008). Genetic redundancy in soybean photoresponses associated with duplication of the phytochrome A gene. Genetics 180, 995-1007. doi: 10.1534/genetics.108. 092742

Lu, H., Lin, T., Klein, J., Wang, S., Qi, J., Zhou, Q., et al. (2014). QTL-seq identifies an early flowering QTL located near FLOWERING LOCUS T in cucumber. Theor. Appl. Genet. 127, 1491-1499. doi: 10.1007/s00122-014-2313-z 
Meyer, R. S., DuVal, A. E., and Jensen, H. R. (2012). Patterns and processes in crop domestication: an historical review and quantitative analysis of 203 global food crops. New Phytol. 196, 29-48. doi: 10.1111/j.1469-8137.2012. 04253.x

Parween, S., Nawaz, K., Roy, R., Pole, A. K., Venkata Suresh, B., Misra, G., et al. (2015). An advanced draft genome assembly of a desi type chickpea (Cicer arietinum L.). Sci. Rep. 5:12806. doi: 10.1038/srep12806

Patel, R. K., and Jain, M. (2012). NGS QC Toolkit: a toolkit for quality control of next generation sequencing data. PLoS ONE 7:e30619. doi: 10.1371/journal. pone.0030619

Pierre, J. B., Bogard, M., Herrmann, D., Huyghe, C., and Julier, B. (2011). A CONSTANS-like gene candidate that could explain most of the genetic variation for flowering date in Medicago truncatula. Mol. Breed. 28, 25-35. doi: 10.1007/s11032-010-9457-6

Pierre, J. B., Huguet, T., Barre, P., Huyghe, C., and Julier, B. (2008). Detection of QTLs for flowering date in three mapping populations of the model legume species Medicago truncatula. Theor. Appl. Genet. 117, 609-620. doi: 10.1007/ s00122-008-0805-4

Pin, P. A., and Nilsson, O. (2012). The multifaceted roles of FLOWERING LOCUS $T$ in plant development. Plant Cell Environ. 35, 1742-1755. doi: 10.1111/j.13653040.2012.02558.x

Radhika, P., Gowda, S. J. M., Kadoo, N. Y., Mhase, L. B., Jamadagni, B. M., Sainani, M. N., et al. (2007). Development of an integrated intraspecific map of chickpea (Cicer arietinum L.) using two recombinant inbred line populations. Theor. Appl. Genet. 115, 209-216. doi: 10.1007/s00122-007-0556-7

Rehman, A. U., Malhotra, R. S., Bett, K., Tar'an, B., Bueckert, R., and Warkentin, T. D. (2011). Mapping QTL associated with traits affecting grain yield in chickpea (Cicer arietinum L.) under terminal drought stress. Crop Sci. 51, 450-463. doi: 10.2135/cropsci2010.03.0129

Saxena, M. S., Bajaj, D., Das, S., Kujur, A., Kumar, V., Singh, M., et al. (2014a). An integrated genomic approach for rapid delineation of candidate genes regulating agro-morphological traits in chickpea. DNA Res. 21, 695-710. doi: 10.1093/dnares/dsu031

Saxena, M. S., Bajaj, D., Kujur, A., Das, S., Badoni, S., Kumar, V., et al. (2014b). Natural allelic diversity, genetic structure and linkage disequilibrium pattern in wild chickpea. PLoS ONE 9:e107484. doi: 10.1371/journal.pone.0107484

Singh, V. K., Garg, R., and Jain, M. (2013). A global view of transcriptome dynamics during flower development in chickpea by deep sequencing. Plant Biotechnol. J. 11, 691-701. doi: 10.1111/pbi.12059

Singh, V. K., Khan, A. W., Jaganathan, D., Thudi, M., Roorkiwal, M., Takagi, H., et al. (2016). QTL-seq for rapid identification of candidate genes for 100seed weight and root/total plant dry weight ratio under rainfed conditions in chickpea. Plant Biotechnol. J. 14, 2110-2119. doi: 10.1111/pbi.12567

Song, Y. H., Ito, S., and Imaizumi, T. (2013). Flowering time regulation: photoperiod- and temperature-sensing in leaves. Trends Plant Sci. 18, 575-583. doi: 10.1016/j.tplants.2013.05.003

Stephens, A., Lombardi, M., Cogan, N. O. I., Foster, J. W., Hobson, K., Materne, M., et al. (2014). Genetic marker discovery, intra-specific linkage map construction and quantitative trait locus analysis of Ascochyta blight resistance in chickpea (Cicer arietinum L.). Mol. Breed. 33, 297-313. doi: 10.1007/s11032-013-9950-9

Takagi, H., Abe, A., Yoshida, K., Kosugi, S., Natsume, S., Mitsuoka, C., et al. (2013). QTL-seq: rapid mapping of quantitative trait loci in rice by whole genome resequencing of DNA from two bulked populations. Plant J. 74, 174-183. doi: $10.1111 /$ tpj.12105

Toker, C. (2009). A note on the evolution of kabuli chickpeas as shown by induced mutations in Cicer reticulatum Ladizinsky. Genet. Resour. Crop Evol. 56, 7-12. doi: 10.1007/s10722-008-9336-8

Upadhyaya, H. D., Bajaj, D., Das, S., Saxena, M. S., Badoni, S., Kumar, V., et al. (2015). A genome-scale integrated approach aids in genetic dissection of complex flowering time trait in chickpea. Plant Mol. Biol. 89, 403-420. doi: $10.1007 / \mathrm{s} 11103-015-0377-\mathrm{z}$
Upadhyaya, H. D., Bramel, P. J., and Singh, S. (2001). Development of a chickpea core subset using geographic distribution and quantitative traits. Crop Sci. 41, 206-210. doi: 10.2135/cropsci2001.411206x

Upadhyaya, H. D., Dwivedi, S. L., Baum, M., Varshney, R. K., Udupa, S. M., and Gowda, C. L. L. (2008). Genetic structure, diversity and allelic richness in composite collection and reference set in chickpea (Cicer arietinum L.). BMC Plant Biol. 8:106. doi: 10.1186/1471-2229-8-106

Vadez, V., Krishnamurthy, L., Thudi, M., Anuradha, C., Colmer, T. D., Turner, N. C., et al. (2012). Assessment of ICCV2 2 JG62 chickpea progenies shows sensitivity of reproduction to salt stress and reveals QTLs for seed yield and yield components. Mol. Breed. 30, 9-21. doi: 10.1007/s11032-011-9594-6

Varshney, R. K., Song, C., Saxena, R. K., Azam, S., Yu, S., Sharpe, A. G., et al. (2013). Draft genome sequence of chickpea (Cicer arietinum) provides a resource for trait improvement. Nat. Biotechnol. 31, 240-246. doi: 10.1038/nbt.2491

Varshney, R. K., Thudi, M., Nayak, S. N., Gaur, P. M., Kashiwagi, J., and Krishnamurthy, L. (2014). Genetic dissection of drought tolerance in chickpea (Cicer arietinum L.). Theor. Appl. Genet. 127, 445-462. doi: 10.1007/s00122013-2230-6

Watanabe, S., Harada, K., and Abe, J. (2012). Genetic and molecular bases of photoperiod responses of flowering in soybean. Breed. Sci. 61, 531-543. doi: $10.1270 /$ jsbbs.61.531

Watanabe, S., Hideshima, R., Xia, Z., Tsubokura, Y., Sato, S., Nakamoto, Y., et al. (2009). Map-based cloning of the gene associated with the soybean maturity locus E3. Genetics 182, 1251-1262. doi: 10.1534/genetics.108.098772

Watanabe, S., Xia, Z., Hideshima, R., Tsubokura, Y., Sato, S., and Yamanaka, N. (2011). A map-based cloning strategy employing a residual heterozygous line reveals that the GIGANTEA gene is involved in soybean maturity and flowering. Genetics 188, 395-407. doi: 10.1534/genetics.110.125062

Weller, J. L., Hecht, V., Liew, L. C., Sussmilch, F. C., Wenden, B., Knowles, C. L., et al. (2009). Update on the genetic control of flowering in garden pea. J. Exp. Bot. 60, 2493-2499. doi: 10.1093/jxb/erp120

Weller, J. L., and Martínez, R. O. (2015). Genetic control of flowering time in legumes. Front. Plant Sci. 6:207. doi: 10.3389/fpls.2015.00207

Yamashino, T., Yamawaki, S., Hagui, E., Ueoka-Nakanishi, H., Nakamichi, N., Ito, S., et al. (2013). Clock-controlled and FLOWERING LOCUS T (FT)dependent photoperiodic pathway in Lotus japonicus I: verification of the flowering-associated function of an FT homolog. Biosci. Biotechnol. Biochem. 77, 747-753. doi: 10.1271/bbb.120871

Zaman-Allah, M., Jenkinson, D. M., and Vadez, V. (2011). Chickpea genotypes contrasting for seed yield under terminal drought stress in the field differ for traits related to the control of water use. Funct. Plant Biol. 38, 270-281. doi: 10.1071/FP10244

Zhai, H., Lu, S., Liang, S., Wu, H., Zhang, X., Liu, B., et al. (2014). GmFT4, a homolog of FLOWERING LOCUS T, is positively regulated by $E 1$ and functions as a flowering repressor in soybean. PLoS ONE 9:e89030. doi: 10.1371/journal. pone. 0089030

Zhang, D., Cheng, H., Hu, Z., Wang, H., Kan, G., Liu, C., et al. (2013). Fine mapping of a major flowering time QTL on soybean chromosome 6 combining linkage and association analysis. Euphytica 191, 23-33. doi: 10.1007/s10681-012-0840-8

Conflict of Interest Statement: The authors declare that the research was conducted in the absence of any commercial or financial relationships that could be construed as a potential conflict of interest.

Copyright (C) 2017 Srivastava, Upadhyaya, Kumar, Daware, Basu, Shimray, Tripathi, Bharadwaj, Tyagi and Parida. This is an open-access article distributed under the terms of the Creative Commons Attribution License (CC BY). The use, distribution or reproduction in other forums is permitted, provided the original author(s) or licensor are credited and that the original publication in this journal is cited, in accordance with accepted academic practice. No use, distribution or reproduction is permitted which does not comply with these terms. 